\title{
Statement of the IUGB Liaison Officers resulting from the IUGB XXI Congress, Halifax, Canada
}

The focus of the XXI Congress of the International Union of Game Biologists (IUGB) was on wildlife biology and management in forested environments. Plenary and technical papers, when considered as a whole, indicated that there has been substantial progress worldwide in incorporating wildlife habitat into forestry. Most important, recent emphasis has shifted from single species orientation to ecosystems and from stand-level analyses to long-term landscape level planning. Much more work needs to be done in those areas, but the current status and widespread interest is encouraging. It is particularly important that similar shifts in management and research are occurring simultaneously in many areas of the world.

The Liaison Officers Committee of the International Union of Game Biologists encourages further progress in the development of ecosystem management systems that will enable the conservation of biodiversity. However, the Committee also believes that the major problem of knowledge of basic biology of individual species and their interaction with habitat continues to be a weak link in the planning process. Community level analyses and landscape-level plans ultimately depend on our understanding of the ecological linkages of species to habitats. Unfortunately, knowledge of cause and effect relations between animals and their habitat remains very poor. The opening plenary session at the IUGB XXI Congress in Halifax, Canada highlighted a fundamental problem in the interaction of wildlife research with forest management: false expectations regarding the role of science in management models and policy decisions, and the flawed assumption in management decisions that humans can return forest ecosystems to some previous level of diversity and stability. Much wildlife research has been inefficient because it has addressed questions that are too large to be answered unambiguously. It is important to recognize that although management must be based on our scientific understanding of nature, management must go beyond the limits of scientific rigour for developing practical, utilitarian models. On the other hand, research must focus on more narrow, unambiguous questions and development of predictive theory with long-term objectives. Strong, mechanistic theory is essential for reliable knowledge. Wildlife research has been slow to develop such theory because it has often been viewed as "basic research" with only indirect applications for management. We strongly encourage a re-thinking of research priorities and expectations from management. We also hope that forest authorities will promote and support such oriented research programs. We encourage management to be more bold in developing the necessary analytical tools and models. Further, we encourage research to focus more narrowly on developing strong theories of mechanistic processes linking individuals and populations to their habitats. The need for a scientific basis for management is indisputable and that need continues to intensify with greater global demands on forest ecosystems for fibre, water, recreation, and wildlife values. Wildlife science needs to become more efficient, and integrated resource management will benefit in the process.

International Union of Game Biologists XXI Congress, Halifax, August 15-20, 1993 original signed by:

I.D. Thompson, President (Canada) S. Csanyi, Past-President (Hungary) 